\title{
The Happy Accidents of Teaching Aircraft Design
}

\author{
David W. Hall" and Russell M. Cummings ${ }^{\dagger}$ \\ California Polytechnic State University, San Luis Obispo, CA 93407
}

\begin{abstract}
The aircraft design curriculum at Cal Poly has grown and evolved over the past decades to include a full year of senior aircraft design and an introductory aircraft design course in the sophomore year. The combination of sophomore and senior aircraft design courses has created the circumstance where a "cult" of aircraft design has developed. The curriculum is producing students who are enthusiastic and motivated about their education, as well as being competent designers after they graduate. A number of "happy accidents" has led to this fortunate situation, including: allowing the sophomores to perform a full aircraft design, having the sophomores work in the same laboratory as the seniors, and the importance of presenting well-bounded design challenges. Other observations about the design classes are made and recommendations for future improvements are included. These recent experiences have shown us that students often learn more when we "teach" less!
\end{abstract}

\section{Introduction}

great dilemma has long existed in engineering curricula. Capstone design courses have been seen as A just that-capstones. Students are required to complete large numbers of mathematics/science, engineering science, and program-dependent analysis courses before they "complete" their education with design. In aeronautics, this progression has included core instruction in aerodynamics, stability \& control, propulsion systems, and structures, with a supporting cast of coursework in mechanics, strength of materials, electronics, materials science, and social sciences \& humanities. But the skills and abilities that make students successful in their analysis courses often do not serve them well when they take design.

In examining the literature, and taking a hard look at what we were doing in our curriculum, we found that the observations of Robert R. Furgason were very true:

In education, we stress the 'right answer' approach and our graduates do not have a good appreciation that most things we deal with are ambiguous and we seek best answers involving many subjective elements. Our curricula should be modified to incorporate these aspects into the educational process. ${ }^{1}$

So, what is the dilemma? Students often don't see the importance and urgency of learning "supporting" subjects until it is too late! A common undergraduate question is, "I want to design airplanes; why do I have to take calculus/physics/mechanics/etc.?" And our answer is often, "Trust me, you need to know calculus/physics/mechanics/etc. before you can design airplanes!" We sound like parents when we should be showing the students the importance of every subject in context. Only belatedly, when they finally take senior design, do they see why they were taking the long list of subjects in their curriculum. Unfortunately, the damage has already been done, since they have often "slouched" their way through these "supporting" courses, not seeing their importance, and now regretting their inability to remember or understand subject matter. This leads to a great deal of inefficiency in many design courses, where design instructors have to spend countless hours providing remedial instruction in subjects that students have already taken, but not learned.

\footnotetext{
* Lecturer, Aerospace Engineering Department. Lifetime Senior Member, AIAA.

${ }^{\dagger}$ Professor Emeritus, Aerospace Engineering Department, currently Professor of Aeronautics, USAF Academy. Associate Fellow, AIAA.
} 
Industry and $\mathrm{ABET}$ have seen certain aspects of this dilemma and required that engineering programs do a better job of teaching design, but many faculty are at a loss as to how to do this. Industry wants graduates who are educated as aeronautical systems engineers, with an understanding of the following concepts: how an aircraft should be designed, how an aircraft should be built, and how the two relate to each other and to making a profit. ${ }^{2}$ Engineering faculty, however, often have difficulty incorporating design throughout their curricula, either because they are more talented at analysis than design, or because they have little or no knowledge of what constitutes design. The observation goes something like this: "How can we teach them about design when they don't know about the basics?" This perspective has merit and has been put forward by many engineering faculty. ${ }^{3}$ So we have a "chicken and egg" problem to solve: students don't see the connection between analysis and design until they've finished their design course(s), and faculty do not believe that design is possible until analysis coursework is completed.

The purpose of this paper is to build on the evolution of aircraft design courses at Cal Poly and to show how students can be taught "about" design before they know a great deal about the analytical subjects that are necessary to "do" design. Several examples of changes to our sophomore design course are included, many of which were discovered quite by accident: the "happy" accidents of teaching aircraft design.

\section{The Genesis of Aircraft Design at Cal Poly}

The faculty of the Aerospace Engineering Department at Cal Poly have long attempted to create a strong, vibrant aircraft design sequence for our students. ${ }^{4-6}$ The design course has evolved over the past fifty years from a course where students learned how to construct an airplane to courses where they perform detailed preliminary design of an aircraft, including many of its systems. This evolution has been greatly enhanced by Cal Poly's participation in the NASA/University Space Research Association Program (USRA) and NASA's Aircraft Multidisciplinary Design and Analysis Fellowship Program (AMDAF), enabling the department to give students a more intensive aircraft design experience by allowing them to work on realworld design problems. Many of the aircraft design problems were industry-generated, with industry engineers actively involved in the department's instructional program via an advisory board. The board is composed of approximately twenty engineers and engineering managers from a cross-section of the aerospace industry. They supply the support, both financial and technical, which makes our design course(s) successful.

The senior-level aircraft design curriculum at Cal Poly is a well-integrated, intensive, year-long course, requiring prerequisite knowledge in aerodynamics, flight performance, and aircraft structures as well as concurrent knowledge in gas dynamics, propulsion systems, and stability and control. The course includes introductory information on aircraft sizing, aircraft operations, weight estimation, performance requirements, maneuvering, propulsion systems, environmental systems, and configuration layout. Issues that are marginally addressed in the course include environmental impact, economics, and airline requirements.

The design work is conducted in an interdisciplinary fashion, with design groups working as teams for most of the three-quarter sequence. The course culminates in a design review at the end of the year attended by working and retired engineers and managers with expertise in aeronautics, manufacturing, propulsion, maintenance, structures, and control systems who come from Boeing, Lockheed Martin, Northrop Grumman, Rolls Royce, General Electric, United Airlines, as well as NASA and other Government agencies. Students gain valuable insight into the difficulties of designing an aircraft within the constraints of a group project with a deadline. Unfortunately, students were not prepared to work well in teams, with the design course being their first in-depth team engineering experience. In addition, student design skills were often inadequate, which shouldn't be surprising, since they had little or no opportunity to practice the art of design.

So, how could students be given the necessary background in design? A variety of approaches to give students a design experience have been attempted at other universities, including teaming freshman with senior design students, ${ }^{7}$ introducing students to engineering concepts in a unified set of courses in the sophomore year, ${ }^{8}$ and teaching aircraft design with international, multidisciplinary teams. ${ }^{9}$ While we 
admired these approaches, we felt that we needed to develop a course that best tied in with Cal Poly's "learn by doing" educational philosophy.

At the same time that we were seeing the need to increase student design skills, pressures external to the university were demanding improved graduation rates and student throughput. Most universities across the country are currently seeking ways to reduce the total number of units required for graduation, and our engineering curriculum was already at the maximum number of units allowed. Therefore, the overriding restraint on any new approach to design education was that the new material could not add units to the existing curriculum. In addition, the curriculum changes had to provide an integrated approach to design from the freshman year through the senior year, with modules taking place throughout the student's academic career. We believed that these restraints were inviolable. A summary of the thought processes and efforts in creating the curriculum are reviewed in Ref. 10.

There were three main areas within the curriculum which were modified to better prepare the students:

- the freshman engineering curriculum,

- a sophomore introduction to design,

- teaching existing engineering analysis courses from a multidisciplinary perspective.

Faculty have included a team-teaching approach to segments of the curriculum where these issues are relevant. The goal is to integrate the multidisciplinary design approach throughout the curriculum, from freshman engineering courses through master's-level design courses. This includes a new freshman engineering design course, a new CAD/CAM modeling course, a new sophomore design course, and a comprehensive approach to design in the senior design sequence. This formed the basis for the creation of the sophomore design course.

\section{The Sophomore Design Curriculum}

A detailed description of the sophomore design course, AERO 215, may be found in Ref. 11. Given the need to introduce students to design at the sophomore level, we faced the same dilemma that was mentioned earlier ... the students don't "know" enough to perform the design of an aircraft. Therefore, the first need in the course was to teach them "just in time" and "just enough", supplemented with computer tools that allow analysis to be performed at levels beyond the scope of the student's abilities. Perhaps the most important aspects of the sophomore design course, however, is for faculty to mentor students in design philosophy and engineering practice ${ }^{12}$ and for industry involvement with students at an early age. ${ }^{13}$

There were six primary goals of the sophomore design course:

- Introduce students to aeronautical engineering fundamentals;

- Introduce teamwork basics;

- Introduce students to ethical/social considerations in design;

- Introduce conceptual design philosophy;

- Introduce presentation skills; and

- Immerse and mentor students in the design process.

We have found that sophomores can learn a great deal from designing a complex system, in spite of their lack of background knowledge. When technical knowledge is missing, software or semi-empirical design methods are offered to the students. In addition, a large amount of design information is supplied to the students in the classroom and via a course web page. We have used new, innovative aircraft requirements to get the students to think about requirements, markets, and the importance of customer-based thinking in the design cycle. 


\section{The "Happy Accidents" and the Lessons Learned}

Since we wrote about our experiences in teaching the sophomore aircraft design course ${ }^{11}$ we have had a number of "happy accidents" that have helped to make the course better than we had envisioned. The lessons we learned over the past five years have enabled us to improve our teaching of aircraft design to sophomores, incorporate design throughout the curriculum, improve the capstone aircraft design sequence, and teach aircraft design to graduate students as well. ${ }^{14}$ These "happy accidents" go above and beyond the typical logistical improvements that are often made in courses as time goes on (such as re-ordering material, improving demonstrations, etc.), but rather include some significant changes to how material was presented and how the course was taught.

\section{A. Allowing Students to Perform a Full Aircraft Design}

The biggest changes in both the philosophy and the practice of teaching AERO 215 were instigated by the students. ${ }^{11}$ The course was originally structured to introduce students to the basics of classical aerodynamics through a series of lectures the first hour of class. The remaining hours were devoted to team building exercises, discussion of case studies in aerospace engineering ethics, and a tour of the reference area of the campus library. It was not until the fourth week of classes that students were given the task of designing some portion of a general aviation aircraft, usually the wing. One team of students approached the authors, who were team-teaching the course at that time, to design an entire airplane since, as they put it, the wing is the most important part of an airplane so designing the rest couldn't be that hard. The student team did an exemplary job at designing their aircraft, much to the amazement of the faculty members. It was crude by industry standards and missing key secondary considerations, but they covered all the primary design areas.

In Fall Quarter 2000, the authors incorporated the design of an entire aircraft into the course curriculum, starting with a light, twin-engine, general aviation aircraft. California had been plagued by wildfires in the Summer of 2000 , so the design subject was then changed to a new aerial firefighter. The California Department of Forestry sent guest lecturers to talk about what they regarded as key features for an aerial firefighter and the students were turned loose to design one. Some of the other early aircraft designs undertaken included:

- Fall 2000: A light twin-engined general aviation aircraft. The aging fleet of general aviation aircraft offered new opportunities for modern designs.

- Spring 2001: A new aerial firefighter. The California Department of Forestry was seeking a replacement aircraft for their fleet of aging transports and bombers.

- Fall 2001: A Personal Air Vehicle. NASA/Langley Research Center was conducting funded university-level research in this area.

- Spring 2002 through Fall 2003: An Extreme Short Takeoff and landing (ESTOL) regional jet for the California Corridor. NASA/Ames Research Center's Powered Lift Project Office was conducting funded university-level research in this area involving Cal Poly faculty and students so sophomores investigated the effect of takeoff and landing field length on aircraft complexity, size, and cost with each quarter addressing a different field length combination.

- Winter and Spring 2004: A basic-to-advanced military jet trainer for an international market.

- Fall 2004 to present: An intra-theater military transport. Requirements have changed over two years to do a systematic investigation of the effects of takeoff and landing field lengths, payload size and weight, and propulsion system type on aircraft size, weight, and cost. Joe Lusczek at ASC has been particularly helpful in helping us keep these requirements as close to current U.S. Air Force and U.S. Army needs as possible.

The final day of class during the Spring Quarter of 2000 was the first of what became a mini Sophomore Design Symposium. This now occurs the final Thursday of classes every quarter during the academic year. Guests from NASA and industry, several of whom are aero alumni, lend a real-world flavor to the symposium, and the students respond with excellent designs. The guests from industry often respond to the presentations by saying, "These are sophomores?" Members of the winning design team in Spring 2001, 
by the way, later continued their AERO 215 team collaboration, won the AIAA Team Undergraduate Aircraft Design competition in 2003, and formed their own company upon graduation to provide innovative conceptual solutions to a wide variety of engineering challenges.

\section{B. The Synergy of Teaching in the Senior Aircraft Design Lab}

One of the authors (Cummings) took sabbatical during the 2001-2002 academic year and the other (Hall) took over the course. During the previous academic year, AERO 215 sophomores increasingly used design references and computer tools in the Senior Aircraft Design Lab, so the course was moved to that lab in the Fall Quarter of 2001. The move introduced scheduling conflicts between sophomores and seniors but also allowed underclassmen and upperclassmen to interact. Fall quarters in particular, the AERO 215 lab methods are similar to those in AERO 443, the first quarter of the year-long senior design sequence. The similarity in subject matter continues to promote interactions between the two groups of aero students that has four primary effects:

1. Sophomores see seniors following the same design procedures they're trying to learn which reinforces the importance of learning the design process (to both groups).

2. Seniors see sophomores struggling with the same kind of work they're doing and remember their AERO 215 experiences two or three years earlier. This demonstrates how much they've learned in Cal Poly's Aeronautical Engineering program since they took AERO 215.

3. Sophomores see from their design-related interactions with seniors the knowledge they can gain from their core aeronautical courses.

4. Seniors learn the design material even better by mentoring the sophomores.

This interaction, or mentoring, has proved invaluable to both sets of students, and has even created a positive rivalry between the students in the department. They view aircraft design as a proving ground for what they're learning (and have learned) and become excited about the subject. That excitement is contagious, as we continuously have Freshman approaching us asking us to take AERO 215 early! Having both sets of students working together in synergy leads to an "accidental" fulfillment of one of the notions presented in Ref. 13: aircraft design mentoring needs to take place at all levels in order to perpetuate the vision and importance of aircraft design among engineers within the aeronautical community. We have called this the "Trickle Down, Grow Up" approach to teaching design, where the design professor is just one member of a mentoring team, all of whom have profound impact on the students (see Fig. 1).

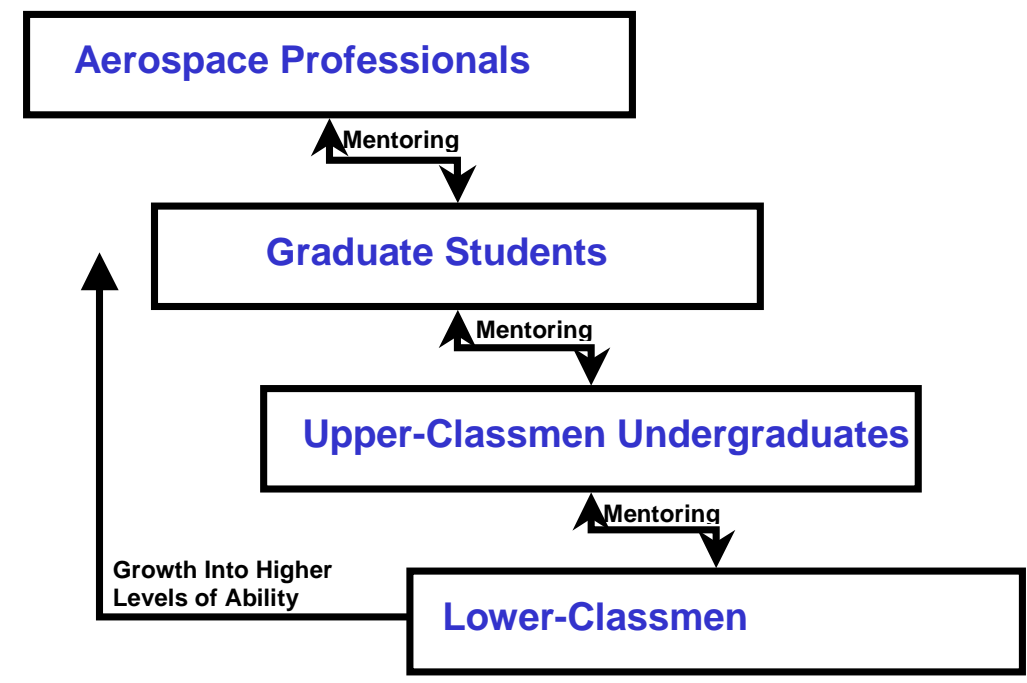

Fig. 1 The “Trickle Down/Grow Up” Mentoring Scheme (Ref. 13). 


\section{The Importance of Well-Bounded Design Challenges}

Ego figures into all human endeavors, try as we might to avoid it, and our teaching of aircraft design to sophomores is no exception. Two or three quarters of success in AERO 215 led to pushing the sophomores into a design project that involved a class of aircraft where no existing consistent historical database exists - personal air vehicles. This turned out to be a learning experience for both the students and the teachers in the importance of having an extensive database of similar aircraft from which to draw upon for preliminary sizing and conceptual design rules of thumb. The students struggled a great deal this quarter with knowing how to appropriately constrain the design space, and many of the resulting designs were quite impractical and immature. It took us awhile to figure out what had gone wrong, but when we realized that a database of existing aircraft was necessary for the sophomores to have a solid foundation, we quickly retreated to a more conventional design topic: regional jet transports.

\section{D. “Just In Time” Teaching Approach}

The "just in time" teaching concept grew out of the "just in time" manufacturing process-have materials and sub-components ready just when they are needed to save time and money. Initially, "just in time" teaching was a concept related to providing students with the information and education they need at the moment they need it. The more formal Just-in-Time-Teaching approach utilizes web-based materials so that students obtain material when they need it. ${ }^{15}$ Our approach, while accidental, was never that formal and, in fact, started spontaneously and largely unnoticed by us.

When the course was initially taught, as mentioned above, the lecture material constituted the first third to half of the academic term, while the design work was usually done over the last one-half to two-thirds of the term. Invariably, the students stated that they wished they had more time to work on the design of their aircraft, but we just could not see how to take away the lecture material, which included the standard atmosphere, basic aerodynamics, and aircraft performance. It took us a few terms before we decided to give the students their design assignments right at the beginning of the term, and to let them slowly get into their designs while we lectured. This approach did not give the students any more time to work on their designs in class, but enabled them to work on the design out of class for the entire academic term.

\section{E. Inclusion of Historic Database Information in Design Process}

After the debacle of trying to design an aircraft in a category where little or no historical data existed in Fall 2001, the authors retreated to aircraft categories with many historical examples and an early assignment every quarter is for sophomores to discover similar types of aircraft to what they'll be designing and to tabulate physical and performance data. They then bring their table to class and the authors create a summary matrix on the board which looks very much like Figure 2. It's always a fun class as students and teachers work together to fill out incomplete data or to make unit conversions from SI to English or miles per hour to knots. This usually leads to sharing design trivia about specific aircraft types the authors have worked on and on basic design philosophy, as in why do classes of airplanes tend to look the way they do. 


\begin{tabular}{|c|c|c|c|c|c|c|c|c|c|c|c|c|c|c|}
\hline Manufacturer & Designation & $\mid \begin{array}{c}\text { TOGW } \\
\text { lb }\end{array}$ & Crew & $\begin{array}{c}\text { Wingspan } \\
\mathrm{ft}\end{array}$ & $\begin{array}{c}O A L \\
\mathrm{ft}\end{array}$ & $\begin{array}{c}O A H \\
f t\end{array}$ & $\begin{array}{c}\text { Wing Area } \\
\text { sq.ft. }\end{array}$ & AR & $\begin{array}{r}\mathrm{C} \\
\text { Length }\end{array}$ & $\begin{array}{l}\text { go B } \\
\text { Vidth }\end{array}$ & Height & $\begin{array}{c}\text { Empty } \\
\mathrm{lb}\end{array}$ & $\begin{array}{c}\text { Payload } \\
\text { Ib }\end{array}$ & $\begin{array}{c}\text { Fuel } \\
\text { lb }\end{array}$ \\
\hline Lockheed Martin & C-130.J & 175,000 & 3 & 132.58 & 97.75 & 38.8 & 1745 & 10.10 & 41 & 10 & 9 & 75,562 & 34,838 & 60,000 \\
\hline Lockheed Martin & $\mathrm{C}-13 \mathrm{OH}$ & 155,000 & 5 & 132.58 & 97.75 & 38.8 & 1745 & 10.10 & 52 & 10 & 9 & 80,000 & 45,000 & 45,900 \\
\hline Antonov & AN-12 & 134,482 & 6 & 124.70 & 108.6 & & 1310 & 11.87 & 44.25 & 11.5 & 8.5 & 61,730 & 44,090 & \\
\hline Antonov & AN-72A & 76,060 & 3 & 104.60 & 92.1 & & 1062 & 10.30 & & & & 41,990 & 22,045 & \\
\hline Boeing (737-700) & $\mathrm{C}-40 \mathrm{~A}$ & 174,000 & 4 & 112.00 & 110 & 41 & & & 58.7 & 10.4 & & 83,000 & 38,700 & 46,063 \\
\hline Airbus & A-400M & & & & & & & & & & & & & \\
\hline Transall & C-160 & 112,000 & 5 & 131.00 & 106.3 & 38 & 1721 & 9.97 & & & & 62,700 & 32,000 & \\
\hline Lockheed Martin (Fiat) & C-27A G222 & 56,878 & & 94.2 & 74.5 & & & & & & & 39,500 & & \\
\hline CASA & C-235 & & & & & & & & & & & & & \\
\hline Short & $\mathrm{C}-23$ & & & & & & & & & & & & & \\
\hline Illyushin & $|1|-214$ & & & & & & & & & & & & & \\
\hline & Y-8 & & & & & & & & & & & & & \\
\hline & $\mathrm{CH}-47$ & & & & & & & & & & & & & \\
\hline
\end{tabular}

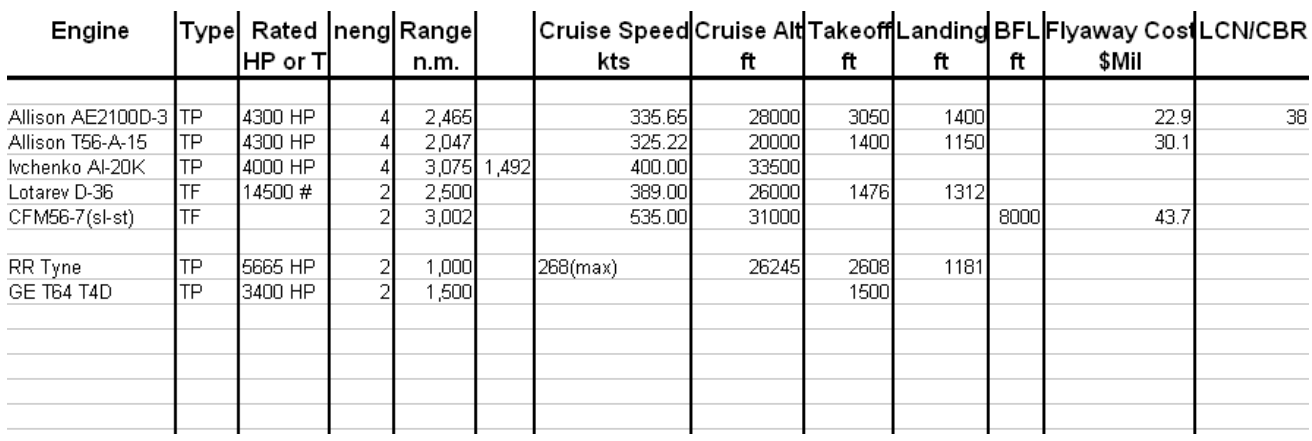

Fig. 2 Example of Historic Database Done By Students.

\section{F. Team-Teaching Approach}

Team-teaching is not a new concept and is probably found to one degree or another at most universities. The variation that has evolved in AERO 215 might more appropriately be labeled tag-team-teaching. Each faculty member who has shared AERO 215 sections has brought unique sets of experience to the course and one of us is almost always in the aircraft design lab when the other is teaching. As a result, answers to student questions will pass back and forth as areas of experience are tapped into. That also leads to extemporaneously sharing stories from personal experience or of colorful people involved in the design of similar aircraft. The energy level in the front of the room builds as a result and that raises the interest level with the students.

\section{G. Other Related Issues}

There are several other related issues that have arisen in our teaching of AERO 215 over the past few years that deserve being mentioned:

- Cal Poly's Mechanical Engineering Department has student exchange agreements with several European universities. The European exchange students occasionally take AERO 215 and invariably do well enough to be invited to stay around over the summer and work on design projects where they usually excel. This interchange is, perhaps, another happy accident of AERO 215. European exchange students have an unparalleled opportunity to interact with U.S. industry and Government engineers and managers and gain a practical feel for an aspect of the aerospace industry that they would not otherwise get to experience in Europe until decades into their careers. Since 2002, exchange students from Sweden, Germany, and Colombia have returned to their countries and established student engineering teams there who consult to their aerospace industry.

- The engineers at the Edwards Air Force Base Flight Test Center have been so impressed with the various aircraft design activities that they have offered Co-operative education placement for Cal Poly students. In spite of the fact that being a Co-op can add a number of quarters to a student's undergraduate experience, several of the students are going to Co-op in order to gain valuable experience. 
- Increased female student retention. Summer internship students are recruited directly from AERO 215 and most years have 30-50\% female members which is above the traditional $5-20 \%$ of females in the program in any given year. The female aero have historically tended to be more mature than their male counterparts and better, more conscientious students, so the percentage has tended to run above the norm. This has led to the happy accident of higher retention rates among females in the Cal Poly aero program.

- The competitive atmosphere during AERO 215 psyches sophomores up to do well later in AIAA (undergraduate and graduate team and individual aircraft design, team engine design, designbuild-fly) and SAWE (annual international student paper) competitions. Holding AERO 215 in the aircraft design lab where seniors are focused on the AIAA competition instills an appreciation for the level of work (and commitment) necessary do successfully compete. Sophomores learn early on that Cal Poly aero is a strong program and they have a shot, if they want it, of doing well competing in AIAA competitions when they get to senior design.

- During Fall 2004, a colleague offered to teach a one-day creativity workshop as part of both the sophomore and senior design courses as a way of developing the workshop and determining how material much change when presented to students. It's always a fun class and leads to discussion of nonlinearities which occur in everyone's careers and to how engineers really work in industry. Recent senior design proposals in AIAA competitions have shown more appreciation for thinking out of the box as a result of this workshop. Ref.16.

\section{Conclusions}

With these many happy accidents, AERO 215 changed from a relatively dry introductory aero course to the breeding ground for aero students trained in the basics of conceptual design who could assist seniors and graduate students with design-related contract research. This research takes place in the aircraft design lab every summer and involves funded research tasks from industry and Government agencies, predominantly NASA/Ames Research Center's Extremely Short TakeOff and Landing (ESTOL) Vehicle Systems Program Office. The statements of work every summer would be immediately recognizable by engineers and managers in advanced concepts groups as systematic examinations of fundamental questions relating to the design of specific types of aircraft. In 2002, one NASA manager coined the term SWAT (Students With ATitude) to describe Cal Poly's summer workers and that label was immediately adopted by the students. These summer teams are composed of incoming juniors (first year team members), fourth year seniors (second year team members), post senior design fifth year seniors (third year team members), and a few graduate students, all of whom did their undergraduate work at Cal Poly. In addition, Cal Poly has done extremely well over the past decade and a half in the AIAA Team (and Individual) Aircraft Design Competition. There is no question in our minds that the quantity and quality of aircraft design work done at Cal Poly is directly related to the learning experiences the students gain in AERO 215.

\section{Acknowledgments}

The authors wish to thank the hundreds of students who have taken our sophomore aircraft design course for their feedback, suggestions, and unknowing contributions to the improvements in our teaching methods. Without their participation we would not have known how to improve our course. In addition, the sophomore aircraft design course has been given a great deal of moral support from various engineers in the aerospace industry and at government labs, which has helped to make the course much more real to our students. Finally, we want to thank John McMasters of The Boeing Company for his support of our ideas and many fruitful (and enjoyable) discussions about aircraft design education, Dr. John Zuk, Doug Wardwell, and Craig Hange at NASA/Ames Research Center for their continuing support of AERO 215 and the Cal Poly SWAT team, and Joe Lusczek at Air Force Air Systems Command for his assistance in developing realistic, real-world RFPs for our sophomores.

\section{References}

${ }^{1}$ Furgason, R.R., "Update on ABET Accreditation Activities," ABET Memo to Engineering Deans, April 1994. 
${ }^{2}$ Nicolai, L.M., "An Industry View of Engineering Design Education," AIAA $31^{\text {st }}$ Aerospace Sciences Meeting, Reno NV AIAA Paper 93-0328, Jan. 1993.

${ }^{3}$ Roskam, J., "What is Needed to Teach Aeronautical Engineering Students How to Design Aircraft?," AIAA, AHS, and ASEE Aircraft Design, Systems and Operations Conference, Dayton OH, AIAA Paper 90-3257, Sept. 1990.

${ }^{4}$ Sandlin, D.R. and van't Riet, R., "The Cal Poly Aircraft Design Program," AIAA, AHS, and ASEE Aerospace Design Conference, Irvine CA, AIAA Paper 93-1111, Feb. 1993.

${ }^{5}$ Soban, D.S., “Aircraft Design Education—A Student's Perspective," AIAA Aircraft Design, Systems, and Operations Meeting, Monterey CA, AIAA Paper 93-3993, Aug. 1993.

${ }^{6}$ Cummings, R.M., "From Biplanes to Reusable Launch Vehicles: 75 Years of Aircraft Design at Cal Poly," AIAA 41st Aerospace Sciences Meeting, Reno NV, AIAA Paper 2003-0233, Jan. 2003.

${ }^{7}$ Marchman, J.F. and Mason, W.H., "Freshman/Senior Design Education," AIAA $32^{\text {nd }}$ Aerospace Sciences Meeting, Reno NV, AIAA Paper 94-0857, Jan. 1994.

${ }^{8}$ Hollister, W.M., Crawley, E.F., and Amir, A.R., "Unified Engineering: A Twenty Year Experiment in Sophomore Aerospace Education at MIT," AIAA $32^{\text {nd }}$ Aerospace Sciences Meeting, Reno NV, AIAA Paper 94-0851, Jan. 1994.

${ }^{9}$ Jenkinson, L.R., Page, G.J., and Marchman, J.F., "Model for International Teaming in Aircraft Design Education," Aircraft Design, Vol. 3, No. 4, 2000, pp. 239-247.

${ }^{10}$ Cummings, R.M. and Freeman, H.J., "Integrating Multidisciplinary Design in an Undergraduate Curriculum," AIAA, NASA, and ISSMO $6^{\text {th }}$ Symposium on Multidisciplinary Analysis and Optimization, 6th, Bellevue WA, AIAA Paper 97-5574, Oct 1997.

${ }^{11}$ Cummings, R.M. and Hall, D., "Aircraft Design for Sophomores," AIAA 40th Aerospace Sciences Meeting, Reno NV, AIAA Paper 2002-0958, Jan. 2002 and "Aircraft Design for Second-Year Undergraduate Students," International Journal of Engineering Education, Vol. 21, No. 2, 2005, pp. 341349 .

${ }^{12}$ McMasters, J.M. and Cummings, R.M., "Aircraft Design—Past, Present, and Future," Journal of Aircraft, Vol. 39, No. 1, 2002, pp. 10-17.

${ }^{13}$ Cummings, R.M. and McMasters, J.M., "Technology and You: Working with the Aerospace Industry to Enhance Engineering Education," ASEE Annual Meeting, Portland OR, ASEE Paper 2005-0925, June 2005 .

${ }^{14}$ Biezad, D.J. and Kim, J., "Constructing General Aviation Aircraft in the Aerospace Lab Courses," ASEE Annual Meeting, Portland OR, ASEE Paper 2005-2576, June 2005.

${ }^{15}$ Gavrin, A., Watt, J.X., Marrs, K., and Blake, R.E., "Just-in-Time Teaching (JiTT): Using the Web to Enhance Classroom Learning," Computers in Education Journal, Vol. 14, No. 2, 2004, pp. 51-60.

${ }^{16}$ Cummings, D.B. and Hall, D.W., "Exploiting the Creative Process for Innovative Air Vehicle Design," AIAA $42^{\text {nd }}$ Aerospace Sciences Meeting, AIAA Paper 2004-0417, Jan. 2004. 